\title{
Incorporating Early-Life History Parameters in the Estimation of the Stock-Recruit Relationship of Georges Bank Atlantic Cod (Gadus morhua)
}

\author{
L. O'Brien, P. J. Rago and R.G. Lough \\ National Marine Fisheries Service, Northeast Fisheries Science Center \\ Woods Hole Laboratory, 166 Water Street, Woods Hole, Massachusetts 02543, USA \\ and \\ P. Berrien \\ National Marine Fisheries Service, Northeast Fisheries Science Center \\ James J. Howard Marine Sciences Laboratory, 74 Magruder Road \\ Highland, New Jersey 07732, USA
}

\begin{abstract}
The determination of stock status and estimation of biological reference points for management of commercially important species often relies on a spawning stock-recruit function which typically assumes that spawners of all ages contribute equally to recruitment. Recent studies of cod (Gadus morhua), however, indicate that the viability of eggs spawned by large and old fish is greater than that of small and young fish. The current stock-recruit relationship for the Georges Bank Atlantic cod stock is based on recruitment of age 1 fish and spawning stock biomass (SSB) derived from virtual population analysis for 1978-2000. The stock-recruit relationship was re-examined by three component stages: egg production as a function of SSB, larval production as a function of egg production, and recruitment as a function of larval production. A statistically significant relationship $(P<0.05)$ was detected for the eggs-SSB (1978-98) component but not for the eggs-larvae and larvae-recruits components although positive trends were observed during the time series (1978-86). Stepwise multiple regression suggests that the age diversity of repeat spawners, spatial distribution of spawned eggs, and bottom temperature contribute significantly to the estimation of variance in egg survivorship for the years 1979-98 $\left(r^{2}=0.54\right)$. The results of the eggs-SSB analysis support conclusions of other studies that repeat spawners have better survival of eggs and early larvae. In addition, these results emphasize that not only the total weight of SSB but also the age diversity of SSB contributes to enhanced recruitment.
\end{abstract}

Key words: Cod, eggs, Gadus morhua, Georges Bank, larvae, regression, spawning stock biomass, stock-recruitment.

\section{Introduction}

Recruitment of most New England groundfish, including Georges Bank Atlantic cod (Gadus morhua), has been shown to be influenced by density-dependent processes; however the functional form of the stockrecruitment relationship is undetermined (Brodziak et al., 2001). The stock-recruit function for Georges Bank cod is currently described by the customary relationship between spawning stock biomass (SSB) and recruitment at age (Fig. 1). In several other cod stocks, alternative measures of reproductive potential have been used to explain recruitment variability. For the Icelandic cod stock, age diversity of the spawning stock and SSB together account for more of the variation in recruitment than SSB alone (Marteinsdottir and Thorarinsson, 1998). A bioenergetic index, based on liver condition indices, has been used as an alternative measure of reproductive potential in Northeast Arctic cod (Marshall et al., 2000).

The typical stock-recruit relationship (Fig. 1) can be modeled alternatively as the product of spawning stock biomass and survival rates of successive life stages that generate recruitment. Hypothetical examples of egg, larval, and recruit survival are presented in Fig. 2. All life stages are measured with considerable sampling error and many sources of 


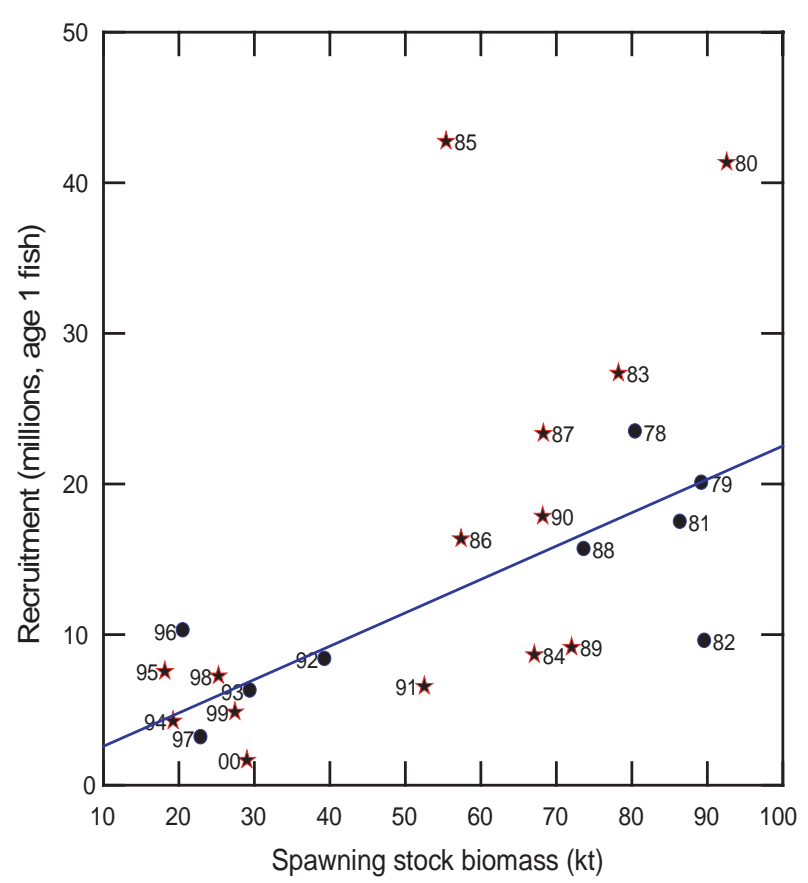

Fig. 1. Spawning stock biomass (kt) and recruitment at age 1 (millions of fish) of Georges Bank Atlantic cod during 1978-2000 $($ circle $=$ cold years, star $=$ warm years).

mortality can intervene between the egg stage and recruitment to the exploitable stock. Taken together these factors make it difficult to discern the relationship between spawning stock and the number of recruits. In this contribution, we look at the stock-recruit relationship at a dis-aggregated level, utilizing a long history of stock abundance estimates and somewhat shorter time series of life stage specific abundance estimates.

Our objective is to investigate the role of several putative influences on the survival of juvenile cod life stages. We first use life stage information to estimate the underlying survival rates. We then relate these survival rates to one or more biological and oceanographic variables and explicitly test several mechanisms posited in the literature.

\section{Methods}

Biological data used in this analysis of the Georges Bank Atlantic cod stock included spawning stock biomass (mt), recruitment at age 1 (millions of fish), age diversity of spawning stock biomass (SSB) during 1978-2000, egg spawning (number/10 $\mathrm{m}^{2}$ ) and egg hatch abundance (number $\times 10^{12}$ ) during 1978-98, and mean larval hatch density (number $\times 10^{9}$ ) and larval abundance (3-5 mm, 6-8 mm, 9-11 mm, 12-15 mm) during 1977-87. Environmental data consisted of spring bottom temperature anomalies as deduced from bottom temperature $\left({ }^{\circ} \mathrm{C}\right)$ data obtained during Northeast Fisheries Science Center (NEFSC) spring surveys, 1977-2000.

Estimates of SSB and recruitment at age 1 for Georges Bank Atlantic cod were obtained from virtual population analysis (VPA) from 1978-2000 (O'Brien and Munroe, 2001). Stock numbers of fish-at-age estimated by VPA were multiplied by mean weight-at-age and the proportion of fish mature-at-age to obtain SSB. A simple linear regression model was fit to the SSB and recruitment data to determine how much variation in recruitment could be explained by SSB alone. In addition, a Beverton-Holt model (Hilborn and Walters, 1992) was fit to the same data using non-linear regression. Both regressions indicated that about $37 \%$ of the variation in recruitment was explained by SSB. The similar regression results and visual examination of the data suggest density dependence in recruitment is not apparent in this stock for the range of data observed (Fig. 1). Linear regression models were, therefore, employed in the remainder of the analyses.

The proportion of fish mature at age was obtained from maturity ogives derived by logistic regression of numbers of mature and immature fish observed (Burnett et al.,1989) during NEFSC spring research surveys, pooled by either 3 or 4 year time blocks (O'Brien and Munroe, 2001). The data were pooled because of the generally low sample size obtained each year. The proportion of first-time spawners for each age within a cohort was estimated as:

where:

$$
P l x_{i j}=P M_{i j}-P M_{i-1, j-1}
$$

$i$ is age,

$j$ is the cohort,

$P M$ is the proportion mature, and

$P 1 x$ is the proportion of first-time spawners.

The proportion of fish that had spawned 2 or more times $\left(P 2 x_{i j}\right)$ for each age and cohort was estimated as: $P 2 x_{i j}=P M_{i j}-P 1 x_{i j}$. The total biomass of repeat spawners was estimated by applying $P 2 x_{i j}$ to the total stock biomass estimated by VPA and discounted for total mortality to the time of spring spawning (O'Brien and Munroe, 2001). 


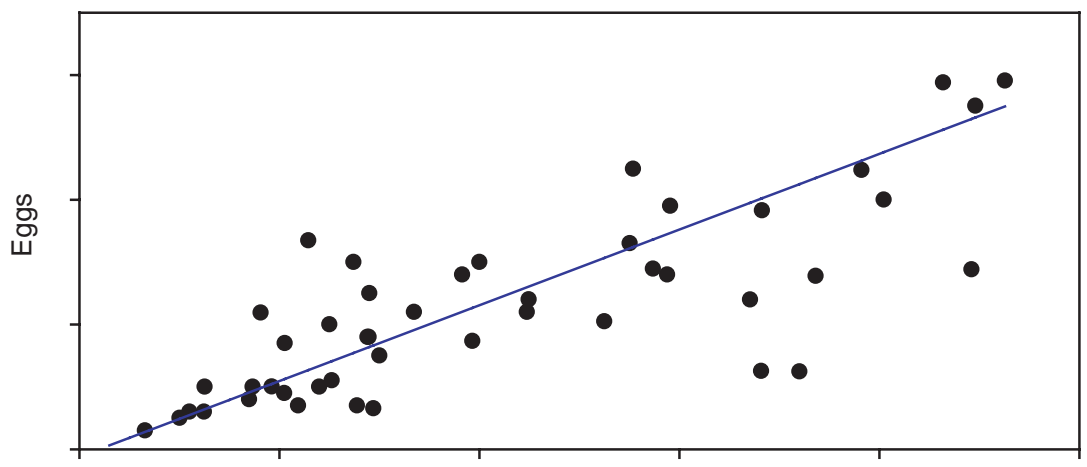

Spawning Stock Biomass
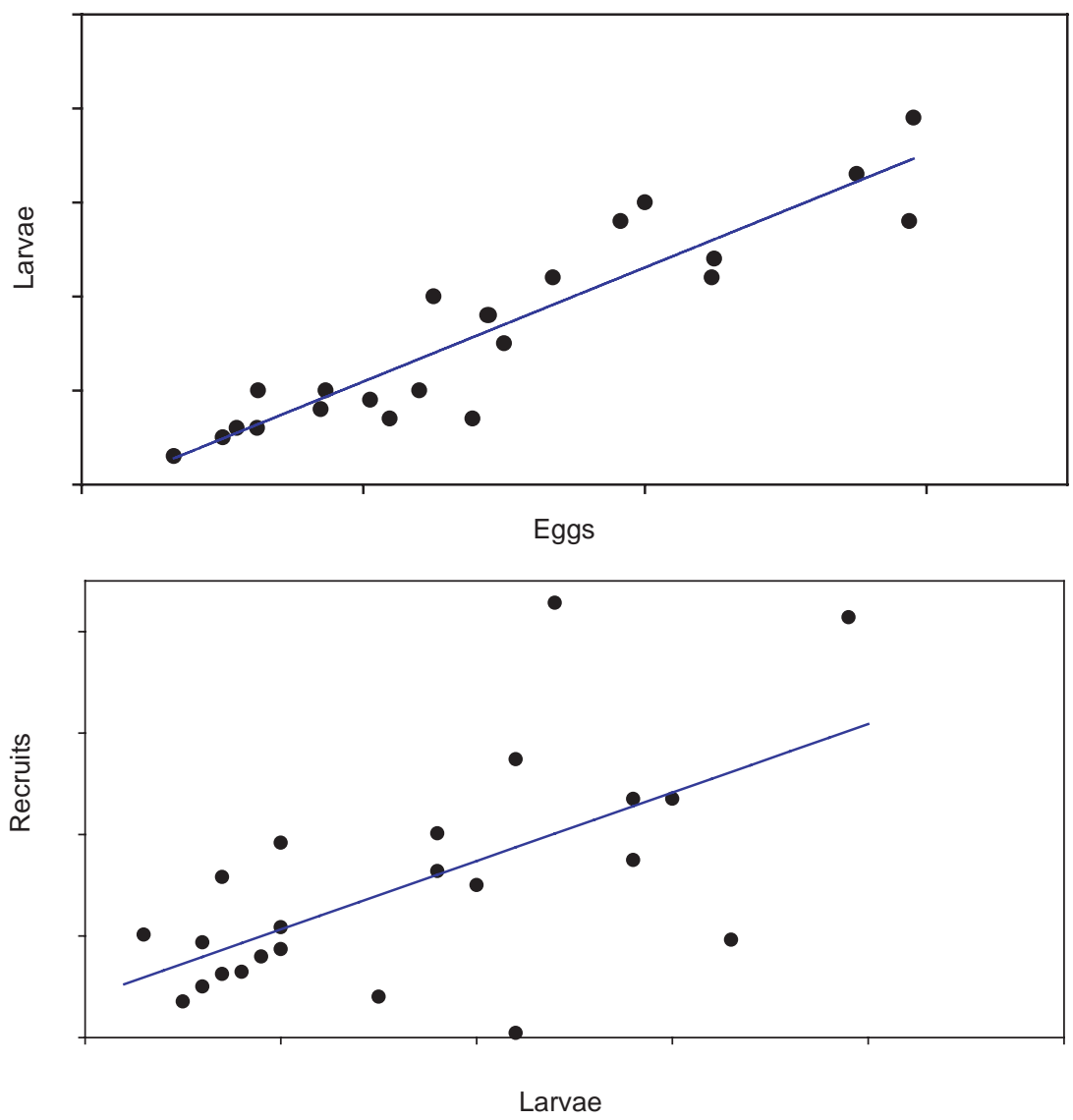

Fig. 2. Alternative stock-recruit relationships for hypothetical data of three successive life-stages: (A) spawning stock biomass vs eggs, (B) eggs vs larvae, and (C) larvae $v s$ recruits.

An age diversity index of spawning stock biomass was derived for both repeat spawners $(2 \mathrm{x}+)$ and all spawners using the Shannon Diversity Index (Shannon, 1948; Marteinsdottir and Thorarinsson, 1998) for mature individuals during 1978-2000. The indices were calculated as:

$$
H=\left(b \log b-\sum_{i=1}^{k} f_{i} \log f_{i}\right) / b
$$

$k$ is the number of age-groups

$b$ is the biomass of mature fish in all age-groups, and $f_{i}$ is the biomass of mature fish in each age group 
Marteinsdottir and Thorarinsson (1998) estimated a similar age diversity index of spawning stock for the number of mature fish at age. Biomass of mature fish was used in this study because biomass is more closely linked with fecundity than is abundance. The age diversity of SSB is more informative than the mean age at spawning, for example, because both the age structure of the spawning stock as well as the number of ages in the spawning stock are taken into account.

Egg and larval data were obtained from ichthyoplankton surveys conducted on Georges Bank during winter and spring months from 1977 to 1998 under three different programs. Marine Resource Monitoring Assessment and Prediction (MARMAP) surveys occurred from 1977 to 1987, Larval Herring (Clupea harengus) surveys occurred from 1988 to 1994 and Global Ocean Ecosystems Dynamics (GLOBEC) surveys occurred from 1995 to 1999. Plankton collection techniques using $60-\mathrm{cm}$ Bongo nets were similar across all surveys, differing substantially only with regard to the mesh size employed. During MARMAP and Larval Herring surveys the mesh size was $0.505 \mathrm{~mm}$ and during GLOBEC it was $0.335 \mathrm{~mm}$; however, towing methods, sample preservation protocols and treatment of the data remained the same. Smooth-oblique tows were made at approximately $1.5 \mathrm{kt}$ to within $5 \mathrm{~m}$ of bottom, or to a maximum of $200 \mathrm{~m}$, and plankton samples were preserved in 5\% formalin. Flowmeters suspended in the mouths of Bongo nets were used to estimate volume filtered, and maximum tow depth was measured with either a bathykymograph (MARMAP and Larval Herring surveys) or with a CTD attached next to the Bongo net yolk. Further details on the methods, timing, and areal coverage are given elsewhere (Sibunka and Silverman, 1984, 1989; Smith and Morse,1993; Berrien and Sibunka, 1999).

All fish eggs and larvae were removed from samples, identified to the lowest taxon possible and then separated into developmental stages (eggs) or measured to the nearest $0.1 \mathrm{~mm}$ (larvae). Initially, eggs were separated into six stages which were then combined into three general stages: from fertilization to blastopore almost closed, blastopore closed to embryo encircling $3 / 4$ of the egg circumference, and greater than $3 / 4$ around until hatching.

Cod and haddock (Melanogrammus aeglefinus) eggs are indistinguishable at developmental stages prior to tail twisting and flexing, and both are confused with witch flounder eggs (Glyptocephalus cynoglossus) before blastopore closure (Fahay, 1983). The development rates of cod and haddock eggs are similar enough to be considered equal (Page and Frank, 1989); therefore, numbers of eggs within these earlier stages were apportioned according to the ratio of older and identifiable stages at the same or adjacent stations.

Larvae were separated into 3 length classes: $3-5$ $\mathrm{mm}, 6-8 \mathrm{~mm}$, and $9-11 \mathrm{~mm}$. The mean age and duration of the length classes were determined from the agelength relationships provided by Bolz and Lough (1988). The mean age and duration of egg and larval stages were based on average incubation period and growth rates and assumed to be constant for all years (Bolz and Lough, 1988; Thompson and Riley, 1981). Larval abundance estimates were adjusted to reflect day, night, and twilight differences in capture vulnerability using correction factors derived by Morse (1989). Bias in the abundance estimate introduced by the extrusion of smaller larvae and escapement of larger larvae is limited by using a truncated length distribution (Morse, 1989) in analyses of hatching densities from larvae. All catches were standardized to number per $10 \mathrm{~m}^{2}$ sea-surface area. Mean density of each stage, derived using a delta-distribution (Pennington and Berrien, 1984), was multiplied by the study area and number of survey days to develop a seasonal abundance estimate.

\section{Methods for Calculating Egg mortality, and for Estimating Egg Production and Hatching Numbers}

For this paper's purposes of summarizing egg densities, estimating egg mortality and subsequently backcalculating numbers spawned and forecasting numbers hatching, egg numbers were grouped into two categories: from just fertilized to the embryo encircling $<3 / 4$ of the egg circumference and a second category of $>3 / 4$ around to hatching. At the typical incubation temperature of $5^{\circ} \mathrm{C}$, these groupings encompass $59 \%$ and $41 \%$ of total development time, respectively (Thompson and Riley, 1981). The null dates for start and end of spawning and hatching on Georges Bank were derived from NEFSC historical ichthyoplankton collection data in conjunction with the above-noted incubation rates.

Numbers of staged eggs collected in Bongo-net tows were standardized to number $10 \mathrm{~m}^{2}$ of sea surface area. Stage duration and stage endpoints were calculated for each collection using the mean integrated water-column temperature as the incubation temperature (Berrien, 1983). Integrated mean water temperatures were used because egg distributions are generally distributed throughout the water column (Lough et al., 1996) and the ichthyoplankton were collected in vertically integrated smooth-oblique tows. These values (number/ $10 \mathrm{~m}^{2}$ and stage endpoints) were 
averaged for each survey (delta-mean number $/ 10 \mathrm{~m}^{2}$ and weighted-arithmetic-mean stage endpoints). The numbers of days represented by each survey were calculated, weighted by station densities of the egg stage in question and centered on the weighted mean date for each survey. Season-long mean density and stage endpoint values were calculated and weighted by station densities and the number of survey days (Berrien et al., 1981).

An average egg mortality rate $(Z)$ was calculated based on the decline in mean stage density over time (stage median age). The rate was estimated by the fitted exponential rate of decline such that:

$$
X_{t}=X_{0} e^{-Z t}
$$

where: $X_{0}$ is egg density (number per $10 \mathrm{~m}^{2}$ ) at age 0 (at spawning),

$X_{t}$ is egg density at age $t$ (days), and

$Z$ is instantaneous rate of decline (mortality coefficient).

This season-long mortality rate was derived using data from all surveys within a given spawning season. It was assumed that any bias caused by assessing mortality during times of increasing or decreasing spawning rates was effectively countered by using data from all portions of the spawning season and then averaging the results.

The estimated mortality rate was used to backcalculate spawned egg densities at each station where earlier-stage eggs were collected. Densities spawned at each station were normalized to daily spawning rates and averaged (delta-mean) across all tows in each survey. A weighted mean spawning date was calculated for each survey, and the time interval (days represented) was calculated extending halfway back and forward to adjacent surveys. Survey spawning rates were expanded by the number of survey days and then summed over the entire season to produce a seasonlong estimate of eggs spawned. Similarly, hatching rates were calculated for each later-stage occurrence, averaged for each survey, expanded over the number of survey days and summed over the season (Berrien et al., 1981; Berrien, 1983).

\section{Methods for Estimating Hatching Densities from Larvae}

Larvae were measured to the nearest $0.1 \mathrm{~mm}$ and ages estimated by the methods used in Bolz and Lough (1988). The data were aggregated into $1-\mathrm{mm}$ intervals for all collection densities of larvae between 5 and
$15 \mathrm{~mm}$ in length in a given spawning season. Plots of these summed densities at age typically described a decline in density over time. Fitting an exponential decline to these points yielded an instantaneous mortality coefficient which was then applied to individual collection densities to estimate corresponding hatching densities for each tow. Similar to egg methods described above, survey mean hatching densities were calculated (delta-mean) from station values of summed hatching densities, then expanded over the entire season by multiplying normalized (per-day) densities by the numbers of days represented for each survey and then summing the survey estimates over the season.

\section{Temperature Data}

Bottom temperature anomalies (Table 1) were estimated from bottom temperature $\left({ }^{\circ} \mathrm{C}\right)$ data obtained on spring and autumn NEFSC bottom trawl surveys conducted during 1970-2000 (Holzwarth and Mountain, 1990; Holzwarth-Davis and Taylor, 1992, 1993, 1994; Taylor and Almgren, 1996a, 1996b; Taylor and Kiladis, 1997; Taylor and Bascunan, 1998, 1999, 2000, 2001). The temperature anomaly series is a more robust measure for examining inter-annual variability in a region than the actual temperature series because differences in the timing of the observations within a survey, and between years has been taken into account. The anomaly represents the difference between the observed temperature and the reference temperature for that location and day of the year the sample was collected (Holzwarth and Mountain, 1990). The reference temperature is based on the annual cycle of temperature at standard station locations derived from hydrographic observations collected during 1977-87 (Mountain, 1989). The reference temperature at each observed survey station was calculated as a weighted average of the reference temperature from the nearest standard stations with the weighting proportional to the $1 / R^{2}$, where $R$ is the separation distance (Holzwarth and Mountain, 1990). The regional average spring temperature anomaly $\left({ }^{\circ} \mathrm{C}\right)$ for Georges Bank was then derived by areal weighting of the anomalies at each of the observed survey stations (Holzwarth and Mountain, 1990). The regional average temperature was also derived by areal weighting (Table 1).

The temperature anomaly is presented in the Figures as a binomial variable by coding each anomaly as 'warm' or 'cold'. Warm years represent those years when the temperature anomaly was 0 or positive and cold years represent those years when the anomaly was 
TABLE 1. Spawning stock biomass (tons), recruitment (millions of age 1 fish), $\ln$ (egg survival), spatial distribution of eggs, and age diversity of repeat spawners for Georges Bank cod and Georges Bank spring research survey areal average temperature $\left({ }^{\circ} \mathrm{C}\right)$ and temperature anomaly $\left({ }^{\circ} \mathrm{C}\right)$ during $1977-2000$.

\begin{tabular}{|c|c|c|c|c|c|c|c|}
\hline Year & $\begin{array}{c}\text { SSB } \\
\text { (tons) }\end{array}$ & $\begin{array}{l}\text { Recruitment } \\
\text { (age 1) }\end{array}$ & $\begin{array}{l}\ln (\text { egg } \\
\text { survival) }\end{array}$ & $\begin{array}{l}\text { Spatial egg } \\
\text { distribution }\end{array}$ & $\begin{array}{l}\text { SSB age } \\
\text { diversity }\end{array}$ & $\begin{array}{l}\text { Temp }\left({ }^{\circ} \mathrm{C}\right) \\
\text { areal mean }\end{array}$ & $\begin{array}{c}\text { Temp }\left({ }^{\circ} \mathrm{C}\right) \\
\text { anomaly }\end{array}$ \\
\hline 1977 & - & - & - & - & - & 6.0 & 0.4 \\
\hline 1978 & 80.4 & 23.5 & - & - & 0.738 & 4.6 & -0.9 \\
\hline 1979 & 89.2 & 20.1 & -3.66 & 0.17 & 0.704 & 5.5 & -0.2 \\
\hline 1980 & 96.6 & 41.4 & -0.58 & 0.22 & 0.757 & 6.5 & 0.7 \\
\hline 1981 & 86.4 & 17.5 & -2.91 & 0.24 & 0.810 & 5.7 & -0.2 \\
\hline 1982 & 89.6 & 9.6 & -4.60 & 0.12 & 0.831 & 5.0 & -0.3 \\
\hline 1983 & 78.2 & 217.4 & -1.69 & 0.13 & 0.834 & 6.0 & 0.7 \\
\hline 1984 & 67.1 & 8.7 & -0.41 & 0.17 & 0.823 & 6.0 & 1.0 \\
\hline 1985 & 55.3 & 42.8 & -0.77 & 0.21 & 0.829 & 5.2 & 0.4 \\
\hline 1986 & 57.4 & 16.4 & -2.38 & 0.11 & 0.817 & 6.4 & 1.4 \\
\hline 1987 & 68.3 & 23.4 & -2.61 & 0.13 & 0.806 & 6.4 & 0.6 \\
\hline 1988 & 73.6 & 15.7 & -3.26 & 0.22 & 0.733 & 4.5 & -0.4 \\
\hline 1989 & 72.0 & 9.2 & -2.65 & 0.22 & 0.706 & 5.0 & 0.0 \\
\hline 1990 & 68.2 & 17.9 & -1.39 & 0.39 & 0.732 & 5.4 & 0.6 \\
\hline 1991 & 52.5 & 6.6 & -1.56 & 0.43 & 0.731 & 5.5 & 0.4 \\
\hline 1992 & 39.3 & 8.4 & 0.24 & 0.36 & 0.817 & 4.2 & -0.6 \\
\hline 1993 & 29.4 & 6.3 & -0.66 & 0.35 & 0.805 & 4.8 & -0.6 \\
\hline 1994 & 19.2 & 4.3 & -1.63 & 0.29 & 0.749 & 5.8 & 0.6 \\
\hline 1995 & 18.1 & 7.6 & -2.85 & 0.23 & 0.675 & 6.3 & 1.1 \\
\hline 1996 & 20.5 & 10.3 & -2.59 & 0.30 & 0.617 & 5.4 & -0.2 \\
\hline 1997 & 22.9 & 3.2 & -4.52 & 0.25 & 0.652 & 5.0 & -0.1 \\
\hline 1998 & 25.2 & 7.3 & -1.98 & 0.38 & 0.754 & 5.3 & 0.4 \\
\hline 1999 & 27.4 & 4.9 & - & - & 0.722 & 5.7 & 0.7 \\
\hline 2000 & 29.0 & 1.7 & - & - & 0.748 & 7.1 & 1.8 \\
\hline
\end{tabular}

negative. The actual bottom temperature anomaly was used in all of the statistical analyses.

\section{Derived Variables}

The following derived variables, based on the estimation of data described above were also used in the analysis: egg survival = egg hatch abundance/egg spawning abundance, $3-5 \mathrm{~mm}$ larval survival $=3-5 \mathrm{~mm}$ larval abundance/egg spawning abundance, $6-8 \mathrm{~mm}$ larval survival $=6-8 \mathrm{~mm}$ larval abundance $/ 3-5 \mathrm{~mm}$ larval abundance, $9-11 \mathrm{~mm}$ larval survival $=9-11 \mathrm{~mm}$ larval abundance $/ 6-8 \mathrm{~mm}$ larval abundance, and recruit survival $=$ recruits $/ \mathrm{SSB}$. An indicator of the spatial distribution of eggs was derived using the ratio of positive tows where eggs were collected to the total number of tows deployed. This proportion represents a measure of the extent of the spatial distribution of eggs over the entire area surveyed.

\section{Statistics}

Data were initially displayed in scatter plot matrices fitted with a bi-square smoother and visually examined to detect possible relationships among variables.
Exploratory simple linear regressions were performed for variables that indicated potential relationships with the dependent variables of egg survival, larval survival and recruit survival. Stepwise multiple regressions were then performed with all variables that influenced the SSB-egg, larval-egg and recruitment-larval relationships to determine which variables significantly $(P<0.05)$ contributed to the variance in the estimation of survival of eggs, larvae, or recruitment.

\section{Results}

Spawning stock biomass (tons), recruitment (millions of age $1 \mathrm{fish}$ ), In egg survival, spatial distribution of eggs, age diversity of repeat spawning biomass for Georges Bank cod and Georges Bank spring bottom temperature anomaly data used in the analyses are presented in Table 1.

Preliminary examination of scatter plots of variables related to SSB and egg abundance during 197998 indicated a significant positive relationship between egg spawning abundance and SSB. The natural loga- 
rithm $(\ln )$ of egg survival was positively correlated with age diversity indices of SSB for all spawners $(1 \mathrm{x}+)$ and repeat spawners $(2 \mathrm{x}+)$, spring bottom temperature anomalies, and spatial distribution of eggs (Fig. 3) but the relationships were not statistically significant.

Stepwise multiple regression analyses indicated that most of the variation (54\%) in egg survival could be explained by the age diversity of repeat spawners (SSB $2 \mathrm{x}^{+}$), bottom temperature anomaly, and the spatial distribution of eggs (Table 2). A similar model with age diversity of all spawners instead of only repeat spawners accounted for $44 \%$ of the variation in egg survival. Over the entire range of age diversity of repeat spawners, egg survival generally appears to be lower and egg distribution narrower during cold years than warm years (Fig. 4). The exceptions are the 1992 and 1993 data points which appear to be outliers. Higher egg survival generally appears to be associated with higher SSB age diversity and wider egg distribution during warm years (Fig. 4).

Preliminary examination of scatter plots of variables related to larvae indicated a positive relationship between egg survival, In egg survival, and bottom temperature anomaly and the abundance of 6-8 $\mathrm{mm}$ larvae and 9-11 $\mathrm{mm}$ larvae and the survival of 6-8 $\mathrm{mm}$ larvae during 1977-87 (Fig. 5a, b). However, only one of these relationships, the abundance of $6-8 \mathrm{~mm}$ larvae (Fig. 5a) was significantly related $(P=0.05)$ to the bottom temperature anomaly. Given the short time series of larval data and the lack of significant positive relationships between egg survival and larval survival, no further regressions were performed.

Preliminary examination of scatter plots of variables related to recruitment indicated a weak positive relationship between $3-5 \mathrm{~mm}$ larval survival and both recruitment (millions of age 1 fish) and recruitment survival during 1979-87 (Fig. 6). No relationships were observed between bottom temperature anomaly and recruitment and recruitment survival during 1978-2000 (Fig. 6). An additional stepwise multiple regression analysis with larval survival and bottom temperature anomaly as the independent variables also did not explain any significant amount of the variability in either recruitment or recruit survival.

\section{Discussion}

Exploratory analysis of the three components of the stock-recruit relationship indicates that survival rather than abundance is the most significant factor contributing to stock-recruitment variability. The stepwise multiple regression results indicated that egg survival is influenced by the environment (bottom tem-

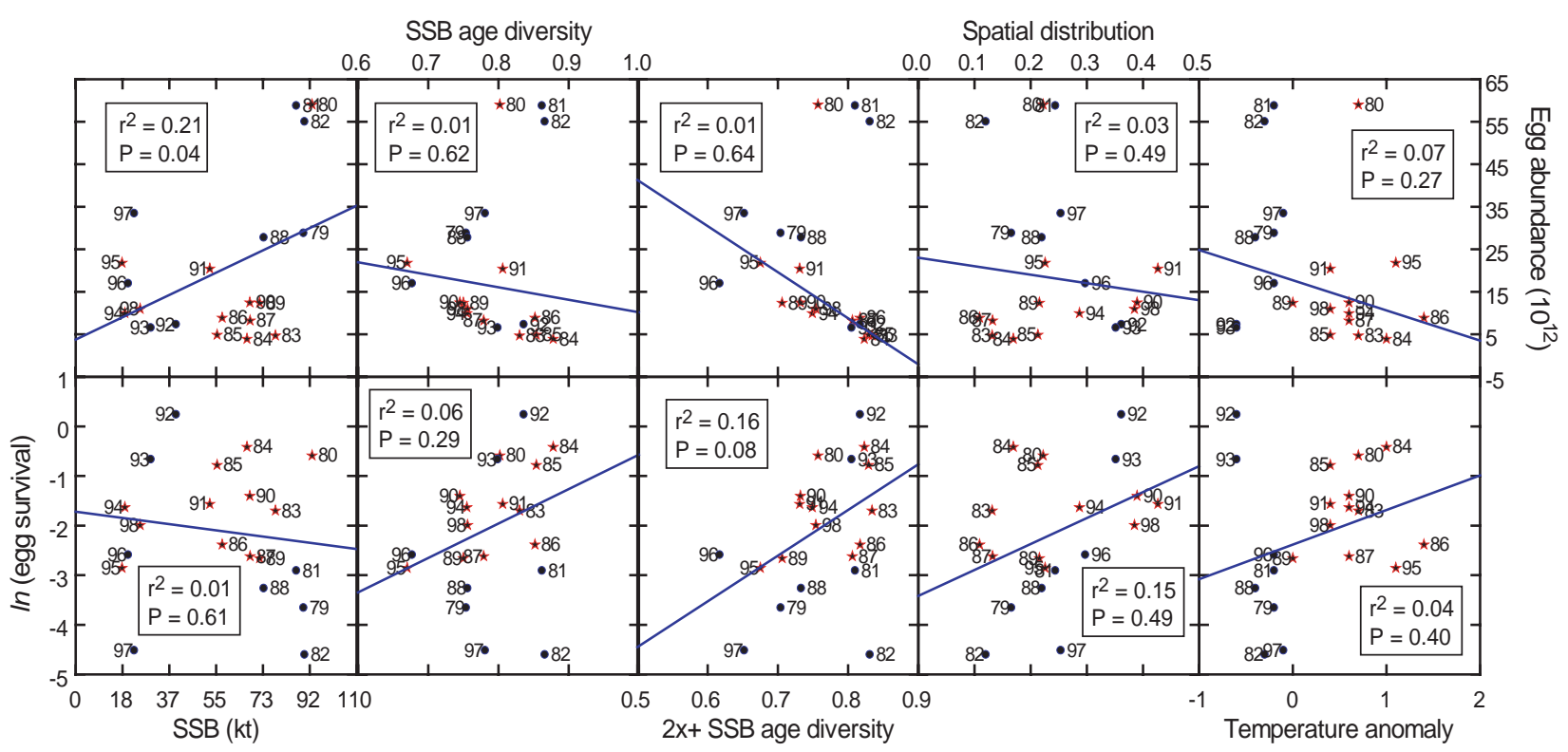

Fig. 3. Scatter plots of egg spawning abundance $\left(10^{12}\right)$ and ln (egg survival) vs spawning stock biomass (SSB), age diversity of all spawners (SSB age diversity), age diversity of repeat spawners ( $2 x+$ SSB age diversity), spatial distribution of eggs, and bottom temperature anomaly during 1978-98. Regression analysis results, $r^{2}$ and probability (P), are provided in each panel $($ circle $=$ cold years, $\operatorname{star}=$ warm years $)$. 
TABLE 2. Stepwise multiple regression models for predicting egg survival and ln (egg survival) with candidate variables: age diversity of spawning stock biomass (SSB) for all spawnwers $\left(1 \mathrm{x}^{+}\right)$and for repeat spawners only $(2 \mathrm{x}+)$, bottom temperature anomally, and spatial distribution of eggs.

\begin{tabular}{|c|c|c|c|c|c|}
\hline $\begin{array}{l}\text { Dependent } \\
\text { variable }\end{array}$ & $\begin{array}{l}\text { Selected independent } \\
\text { variable }\end{array}$ & $\begin{array}{l}\text { No. of } \\
\text { cases }\end{array}$ & $\begin{array}{l}\text { Regression } \\
\text { coefficient }\end{array}$ & $P$ & $R^{2}$ \\
\hline \multirow[t]{2}{*}{ Egg survival } & intercept & & -0.830 & 0.19 & 0.15 \\
\hline & age diversity SSB $1 \times+$ & 20 & 1.299 & 0.11 & \\
\hline \multirow[t]{4}{*}{$\ln$ (egg survival) } & intercept & & -9.999 & 0.02 & 0.44 \\
\hline & age diversity SSB $1 \times+$ & 23 & 7.243 & 0.11 & \\
\hline & bottom temperature anomaly & 23 & 1.086 & 0.03 & \\
\hline & spatial distribution & 20 & 7.120 & 0.02 & \\
\hline \multirow[t]{3}{*}{ Egg survival } & intercept & & -1.265 & 0.05 & 0.27 \\
\hline & age diversity SSB $2 \times+$ & 23 & 1.687 & 0.03 & \\
\hline & spatial distribution & 20 & 0.764 & 0.14 & \\
\hline \multirow[t]{4}{*}{$\ln$ (egg survival) } & intercept & & -11.523 & 0.00 & 0.54 \\
\hline & age diversity SSB $2 \times+$ & 23 & 9.423 & 0.02 & \\
\hline & bottom temperature anomaly & 23 & 0.942 & 0.03 & \\
\hline & spatial distribution & 20 & 7.752 & 0.01 & \\
\hline
\end{tabular}

perature), spatial distribution of eggs, and both spawning experience $(2 \mathrm{x}+$ spawners $)$ and age diversity of the SSB. Of the three components, however, only the SSB and egg data had a sufficiently long (20 years) time series to allow us to detect any significant patterns. The larval data time series was too short (11 years) to detect biologically meaningful trends. The positive trends between the egg and larval data, although weak, do suggest that a longer time series may produce statistically significant relationships.

Variability in the estimate of SSB may have been introduced by applying pooled female-only ogives to total biomass. Throughout the time series, maturity ogives are generally similar between the sexes with estimates of annual median maturity-at-age occurring between ages 2 and 3 for both females and males (O'Brien, 1999). Although the majority of $2^{\text {nd }}$ time spawners are age 2 and age 3 , the consequence of any introduced variability is most likely small since these age-groups comprise on average only about $45 \%$ of the mean biomass and less than $30 \%$ of SSB (O'Brien and Munroe, 2001).

Intuitively, the quantity of eggs produced by a stock should be positively correlated with SSB, as observed in this analysis. More interesting, however, is that egg survivorship was positively related to the age diversity of spawners but not to the magnitude of SSB.
Total biomass of Georges Bank cod has declined since 1980 and age structure has become truncated (O'Brien and Munroe, 2001). Although the dynamic range is not wide (0.617-0.834), the diversity indices derived from VPA population biomass estimates do reflect the contrasting periods of higher age diversity in the mid-1980s and early-1990s and the lower age diversity in the late1980s and mid-1990s. Although fish age 10 and older are landed by the commercial fishery, abundance of these fish is lower in the more recent years compared to the early-1980s (O'Brien and Munroe, 2001). The NEFSC research surveys also indicate that the older larger fish are no longer represented in the population at the higher abundances observed in the mid-1980s. Also, median maturity at length declined slightly during this time period (O'Brien, 1999). These dynamics in the population appear to be reflected in a larger SSB in the early 1980 s that generally produced more viable eggs in higher volume than the smaller SSB in the more recent years (Fig. 3 and Fig. 7).

The empirical evidence that egg survival of Georges Bank cod appears to be linked with wider egg distribution and higher age diversity of repeat spawners, particularly during warm years, is supported by other studies. Maternal characteristics, such as age, length, weight, and condition have been shown to influence egg size and survival (Kjesbu et al., 1992; Marshall et al., 1998; Marteinsdottir and Steinarsson, 


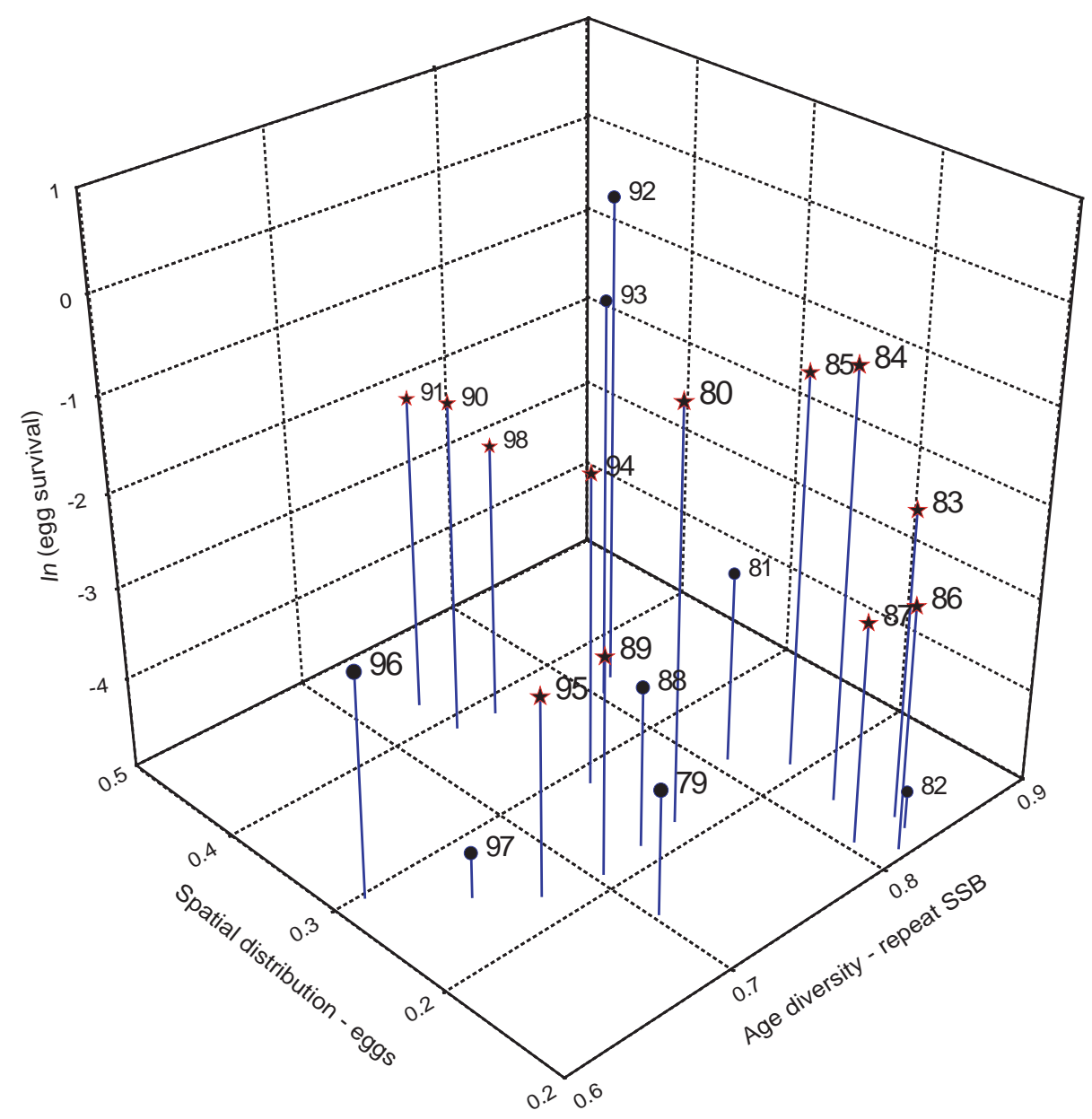

Fig. 4. Age diversity of repeat spawner biomass, spatial distribution of eggs, natural logarithm $(\ln )$ of egg survival rate, and bottom temperature anomaly during 1979$98($ circle $=$ cold years, $\operatorname{star}=$ warm years $)$.

1998). Laboratory studies of egg hatching success in Atlantic cod indicate that hatching success of eggs from second-time spawners is higher $(\sim 62 \%)$ than that of first-time spawners ( 13\%) (Trippel, 1998). Older and larger repeat spawners have larger and more viable eggs that contribute to higher egg survival than those from young, small spawners (Kjesbu et al., 1996; Trippel et al., 1997). Larger eggs produce larger-size larvae at hatching and these larvae feed more successfully and grow faster than larvae from smaller eggs resulting in higher survival rates (Knutsen and Tilseth, 1985; Marteinsdottir and Steinarsson, 1998).

Larger repeat spawners of Atlantic cod spawn for a longer period of time compared to both younger fish and first-time spawners (Kjesbu et al., 1996; Trippel, 1998). The bathymetric and horizontal distributions of eggs from repeat-spawner eggs are greater than those from first- time spawners due to variations in egg buoyancy (Kjesbu et al., 1992). If the spawning stock is spatially or temporally dis-aggregated by age group and is also comprised of a number of age-groups, the distribution of eggs would be expected to be spatially widely dispersed. Conversely, a spawning stock consisting of only a few age-groups should have a less dispersed egg distribution. A more dispersed spatial distribution of eggs should enhance egg survival since the eggs will have a greater opportunity to encounter favorable conditions for survival, i.e. optimum temperature, minimum predation, and retention in the spawning and hatching areas. For example, in a numerical simulation model, particles distributed in depths $>25 \mathrm{~m}$ had greater retention on Georges Bank than particles at depths $<25 \mathrm{~m}$ (Lough et al., 1994). This suggests that the more widely-dispersed eggs at greater depth from repeat spawners may have a better chance of re- 
tention and survival on the Bank than the less-dispersed eggs at shallower depth from first-time spawners.

Temperature can be considered a proxy for other environmental factors that influence growth and survival of the early life history stages for cod as well as other groundfish (Sundby, 2000). Our study revealed that bottom temperature positively affected cod egg and larval survival (as noted in other studies: Ellertsen et al., 1989, Leising and Franks, 1999), but did not affect recruitment or recruitment survival (Fig. 6). The positive effect of temperature on larval survival in our study may be linked indirectly by the availability of their prey species (Sunby, 2000). The major prey items of Georges Bank cod larvae are the life stages of the copepods Calanus and Pseudocalanus sp. (Lough et al., 1996). Production of Calanus and Pseudo-calanus sp. on Georges Bank during the late-autumn to earlyspring (Durbin et al., 1997) coincides with the early life history of Georges Bank cod.

Georges Bank cod may not be characterized by a significant relationship between recruitment survival

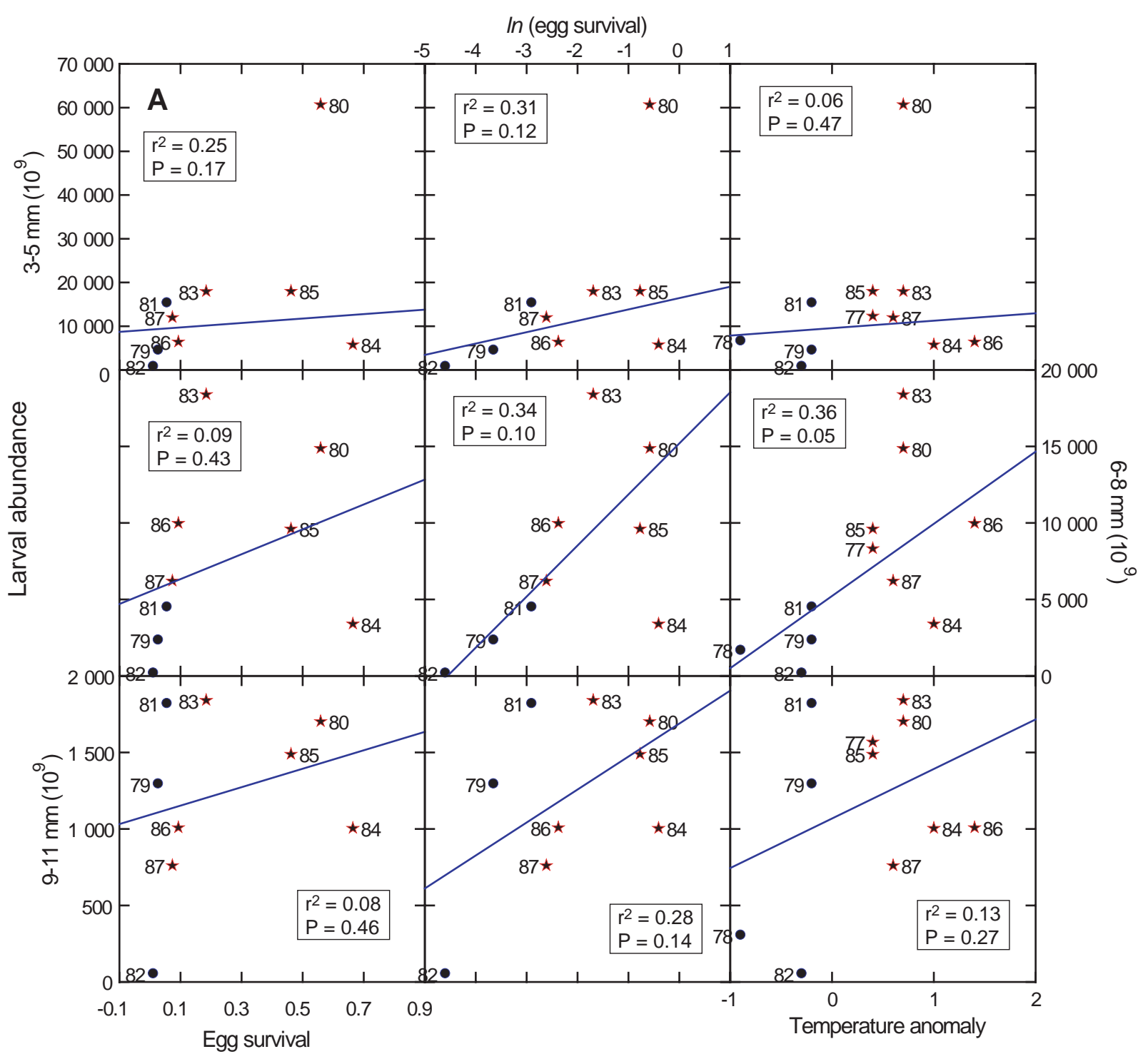

Fig. 5a. Scatter plots of larval abundance (numbers $\times 10^{9}$ ) at 3-5 mm, 6-8 mm, and 9-11 $\mathrm{mm} v s$ egg survival rate, $\ln ($ egg survival) rate, and spring bottom temperature anomaly. Regression analysis results, $r^{2}$ and probability (P), are provided in each panel $($ circle $=$ cold years, $\operatorname{star}=$ warm years $)$. 


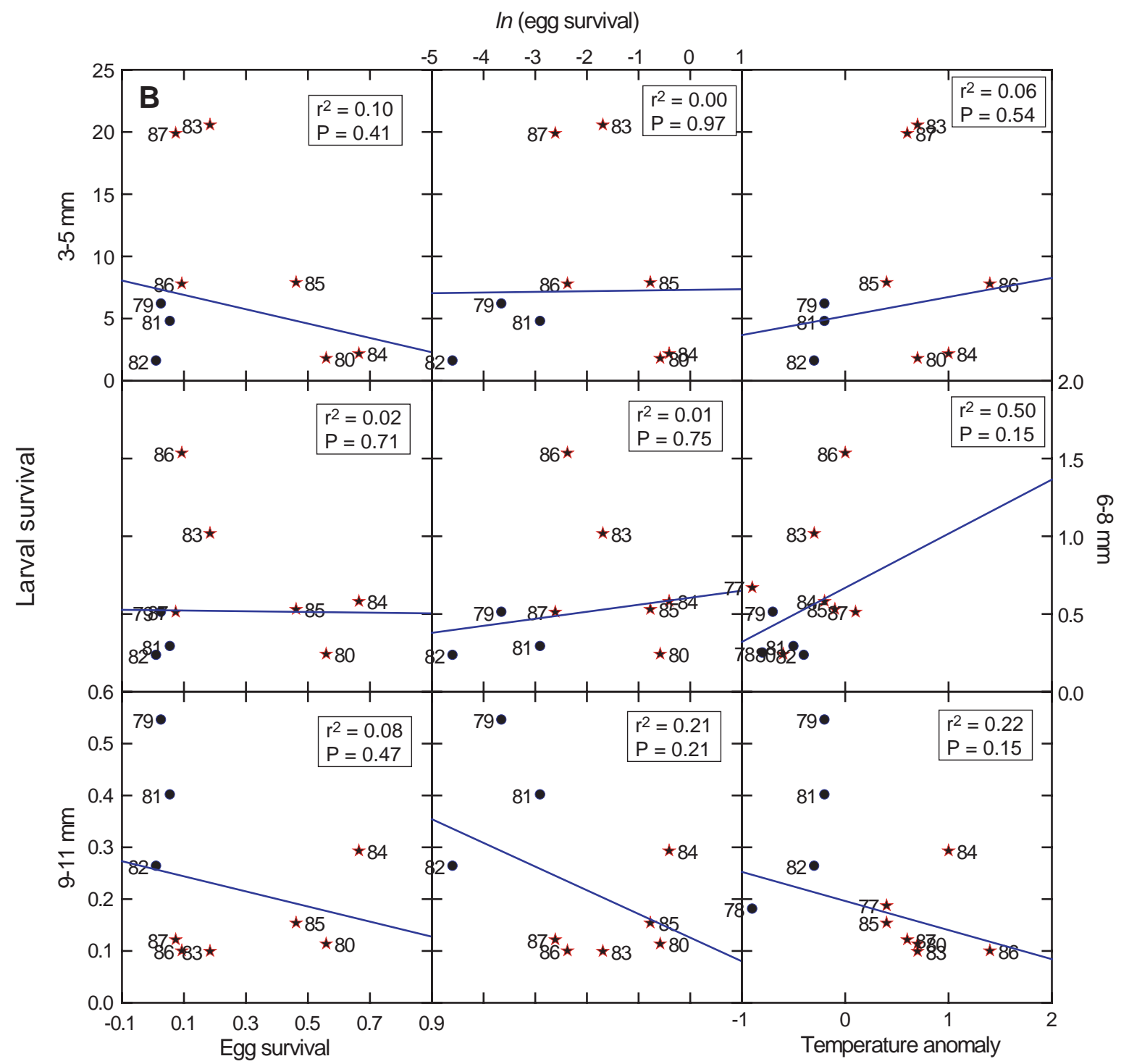

Fig. 5b. Scatter plots of larval survival rate at 3-5 mm, 6-8 mm, and 9-11 mm vs egg survival rate, $\ln$ (egg survival) rate and spring bottom temperature anomaly. Regression analysis results, $r^{2}$ and probability $(\mathrm{P})$, are provided in each panel $($ circle $=$ cold years, star $=$ warm years $)$.

and temperature because the stock inhabits temperate waters near the southern range of the species distribution in the Northwest Atlantic (Collette and KleinMacPhee, 2002). Planque and Fredou (1999) demonstrated that warmer water temperatures negatively affect recruitment of cod stocks inhabiting warm waters, positively affects recruitment of cod stocks inhabiting cold waters, and has no significant effect on recruitment of temperate-water cod stocks. The response of recruitment to temperature is not expected to be linear except for species at the extreme end of their range (Shepherd et al., 1984).
Estimates of SSB are more easily obtained than estimates of egg mortality and for both assessment and management purposes it may not be practical to determine the stock-recruit relationship at individual life stages. However, our study suggests that the current stock-recruit relationship could account for more variation in recruitment by including other variables. Age diversity of SSB and bottom temperature are among the candidate variables that could be incorporated into a reconstructed stock-recruit relationship for Georges Bank Atlantic cod (Marteinsdottir and Thorarinsson, 1998; Cardinale and Arrhenius, 2000; 
Marshall et al., 2000; Murawski et al., 2001; Chen and Irvine, 2001). The biological reference points generated from such an alternative model would more closely measure the stock's capacity to withstand exploitation (Marshall et al., 2000; Murawski et al., 2001).

In the last decade the Georges Bank cod stock appears to have been below a SSB minimum ( $\sim 50000$ tons) in which the stock has not experienced strong recruitment in spite of higher age diversity earlier in the decade and warmer temperature in the more recent years. Although exploitation has decreased, this stock is still being exploited above the maximum fishing mortality threshold (O'Brien and Munroe, 2001). This lack of recruitment, however, is similar to other stocks that have not recovered in spite of lowered exploitation rates (Myers et al., 1995; Frank and Brickman, 2000). Above this SSB minimum more successful recruitment does occur, particularly in warmer years (Fig. 7). Recovery and sustainability of Georges Bank cod is dependent not only upon a critical amount of SSB but on a SSB consisting of diverse age-groups of repeat spawners (Scott et al., 1999). A more diverse age structure in the spawning stock is more likely to result in good recruitment during years when environmental conditions are favorable for producing a strong year-class, as well as a hedge against environmental perturbations.

\section{Acknowledgements}

We appreciate the contribution of all sea-going personnel that have collected these data and thank Dr. D. Mountain for discussions of the oceanographic data and comments on the manuscript and R. Mayo, Dr. F. Serchuk, and two anonymous referees for reviewing the manuscript.

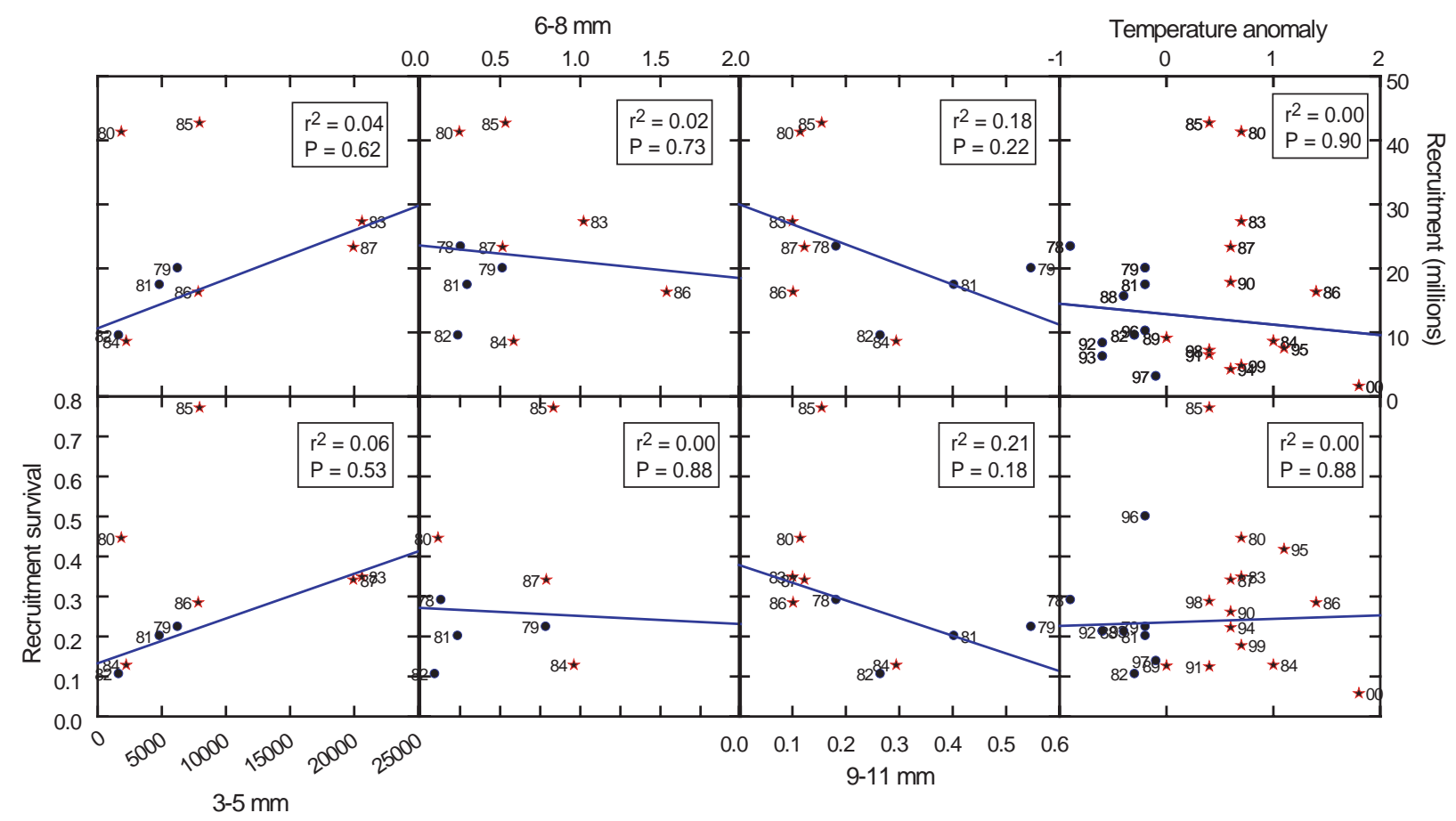

Fig. 6. Scatter plots of recruitment (millions, age 1) and recruitment survival vs larval survival rates of 3-5 mm larvae, 6-8 mm larvae, 9-11 mm larvae, and spring bottom temperature anomaly during 1978-2000. Regression analysis results, $r^{2}$ and probability $(\mathrm{P})$, are provided in each panel $($ circle $=$ cold years, star $=$ warm years $)$. 


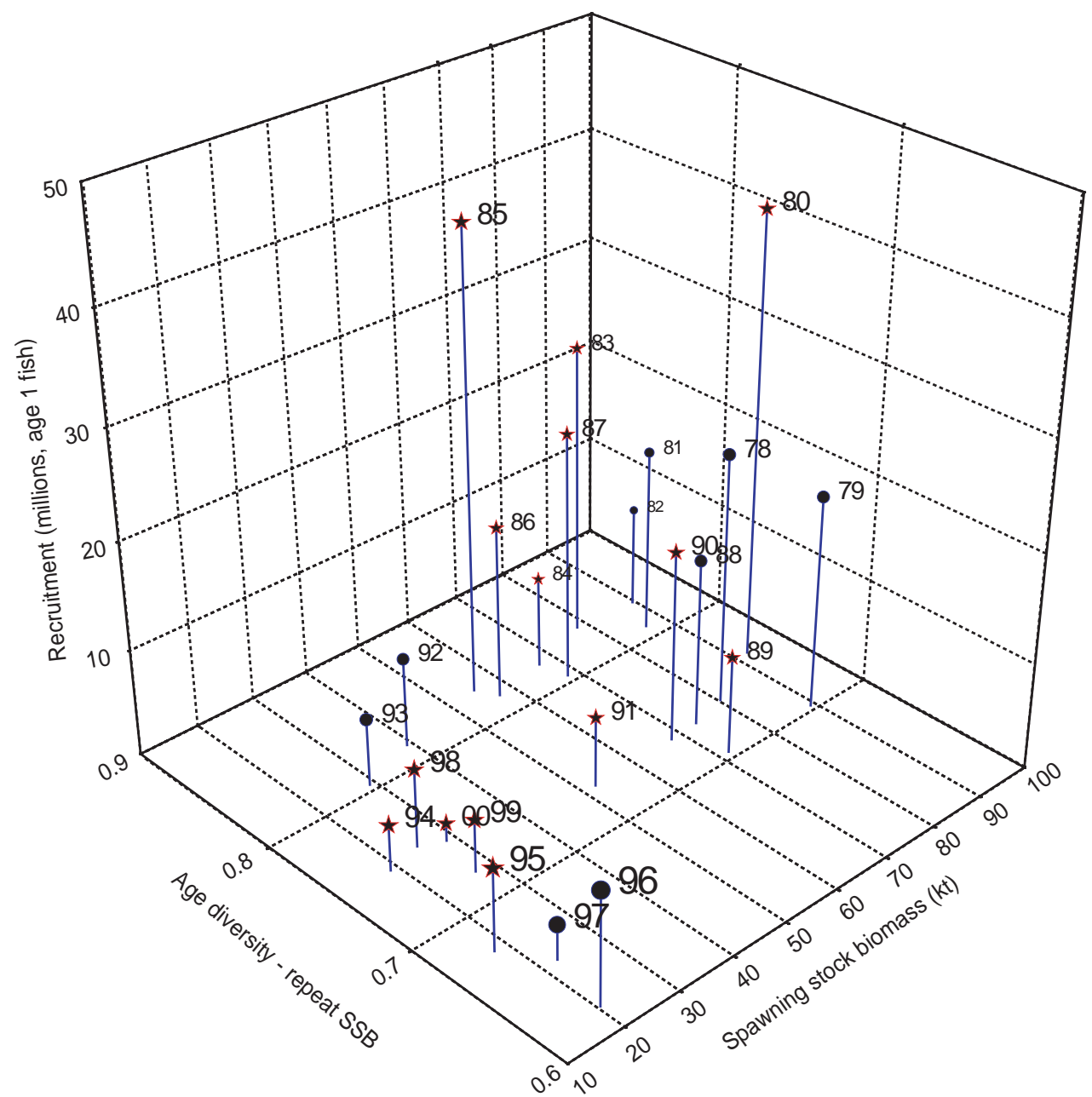

Fig. 7. Spawning stock biomass (kt), age diversity of repeat-spawning stock biomass, recruitment (millions of age 1 fish), and bottom temperature anomaly during 1978$2000($ circle $=$ cold years, star $=$ warm years $)$.

\section{References}

BERRIEN, P. 1983. Silver hake, Merluccius bilinearis, egg census and adult population estimate for 1979 in waters off eastern United States. ICES C.M. Doc., No. G:46 Demersal Fish Comm., 17 p.

BERRIEN, P. L., N. A. NAPLIN, and M. R. PENNINGTON. 1981. Atlantic mackerel, Scomber scombrus, egg production and spawning population estimates for 1977 in the Gulf of Maine, Georges Bank and Middle Atlantic Bight. ICES Rapp. Proc.-Verb., 178: 279-288.

BERRIEN, P., and J. SIBUNKA. 1999. Distribution patterns of fish eggs in the U.S. Northeast continental shelf ecosystem, 1977-1987. NOAA Tech. Rep. NMFS, No. 145: $310 \mathrm{p}$.

BOLZ, G. R., and R. G. LOUGH. 1988. Growth through the first six months of Atlantic cod, Gadus morhua, and haddock, Melanogrammus aeglefinus, based on daily otolith increments. Fish. Bull. U.S., 86: 223-235.

BRODZIAK, J. K. T., W. J. OVERHOLTZ, and P. J. RAGO. 2001. Does spawning stock affect recruitment of New England groundfish? Can. J. Fish. Aquat. Sci., 58: 306-318.

BURNETT, J., L. O'BRIEN, R. K. MAYO, J. A. DARDE, and M. L. BOHAN. 1989. The history of maturity sampling and classification schemes used during the NEFC bottom trawl survey program, 1963-1989. NOAA Tech. Mem. NMFS-F/NEC-76, 14 p.

CARDINALE, M., and F. ARRHENIUS. 2000. The influence of stock structure and environmental conditions on the recruitment process of Baltic cod estimated using a generalized additive model. Can. J. Fish. Aquat. Sci., 57: 2402-2409.

CHEN, D. G., and J. R. IRWINE. 2001. A semiparametric model to examine stock-recruitment relationships incorporating environmental data. Can. J. Fish. Aquat. 
Sci., 58: 1178-1186.

COLLETTE, B. B. and G. KLEIN-MACPHEE. (eds.). 2002. Bigelow and Schroeder's Fishes of the Gulf of Maine. $3^{\text {rd }}$ edition. Smithsonian Institution Press. Washington, $748 \mathrm{p}$.

DURBIN, E. G., J. A. RUNGE, R. G. CAMPBELL, P. R. GARRAHAN, M. C. CASAS, and S. PLOURDE. 1997. Late fall-early winter recruitment of Calanus finmarchicus on Georges Bank. Mar. Ecol. Prog. Ser., 151: $103-114$.

ELLERTSEN, B., P. FOSSUM, P. SOLEMDAL, and S. SUNDBY. 1989. Relation between temperature and survival of eggs and first-feeding larvae of northeast Arctic cod (Gadus morhua L.). ICES Rapp. Proc.-Verb., 191: 209-219.

FAHAY, M.P. 1983. Guide to the early stages of marine fishes occurring in the western North Atlantic Ocean, Cape Hatteras to the southern Scotian Shelf. J. Northw. Atl. Fish. Sci., 4: 1-423.

FRANK, K. T., and D. BRICKMAN. 2000. Allee effects and compensatory population dynamics within a stock complex. Can. J. Fish. Aquat. Sci., 57: 513-517.

HILBORN, R., and C. J. WALTERS. 1992. Quantitative fisheries stock assessment: choice, dynamics and uncertainty. Chapman and Hall, New York, 570 p.

HOLZWARTH-DAVIS, T. J., and M. H. TAYLOR. 1992. Description of the 1991 oceanographic conditions on the Northeast Continental Shelf. NEFSC, Woods Hole Laboratory, Lab. Ref. Doc., 92-08: 54 p.

1993. Description of the 1992 oceanographic conditions on the Northeast Continental Shelf. NEFSC, Woods Hole Laboratory, Lab. Ref. Doc., No. 93-25: $87 \mathrm{p}$.

1994. Description of the 1993 oceanographic conditions on the Northeast Continental Shelf. NEFSC, Woods Hole Laboratory, Lab. Ref. Doc., No. 94-11: $80 \mathrm{p}$.

HOLZWARTH, T. J., and D. MOUNTAIN. 1990. Surface and bottom temperature distributions for the Northeast Fisheries Center spring and fall bottom trawl survey program, 1963-1987 with addendum for 1988-1990. NEFSC, Woods Hole Laboratory, Lab. Ref. Doc., 90-03, (Revised October 1992): 62 p.

KJESBU, O. S., H. KRYVI, S. SUNDBY, and P. SOLEMDAL. 1992. Buoyancy variations in eggs of Atlantic cod (Gadus morhua L.) in relation to chorion thickness and egg size: theory and observations. J. Fish Biol., 41: 581-599.

KJESBU, O. S., P. SOLEMDAL, P. BRATLAND, and M. FONN. 1996. Variation in annual egg production in individual captive Atlantic cod (Gadus morhua). Can. J. Fish. Aquat. Sci., 53: 610-620.

KNUTSEN, G. M., and S. TILSETH. 1985. Growth, development and feeding success of Atlantic cod larvae Gadus morhua related to egg size. Trans. Am. Fish. Soc., 114: 507-511.

LEISING, A. W., and P. J. S. FRANKS. 1999. Larval Atlantic cod (Gadus morhua) and haddock (Melanogrammus aeglefinus) growth on Georges Bank: a model with temperature, prey size, and turbulence forcing. Can. J. Fish. Aquat. Sci., 56: 25-36.

LOUGH, R. G., E. M. CALDRONE, T. K. ROTUNNO, E. A. BROUGHTON, B. R. BURNS, and L. J. BUCKLEY. 1996. Vertical distribution of cod and haddock eggs and larvae, feeding and condition in stratified and mixed waters on southern Georges Bank, May 1992. Deep-Sea Res. II, 43: 1875-1904.

LOUGH, R. G., W. G. SMITH, F. E. WERNER, J. W. LODER, F. H. PAGE, C. G. HANNAH, C. E. NAIMIE, R. I. PERRY, M. SINCLAIR, and D. R. LYNCH. 1994. Influence of wind-driven advection on interannual variability in cod egg and larval distributions on Georges Bank: 1982 vs 1985. ICES Mar. Sci. Symp., 198: 356-378.

MARSHALL, C. T., O. S. KJESBU, N. A. YARAGINA, P. SOLEMDAL, and Ø. ULLTANG. 1998. Is spawner biomass a sensitive measure of the reproductive and recruitment potential of Northeast Arctic cod? Can. J. Fish. Aquat. Sci., 55: 1766-1783.

MARSHALL, C. T., N. A. YARAGINA, B. ADLANDSVIK, and A. V. DOLGOV. 2000. Reconstructing the stockrecruit relationship for Northeast Arctic cod using a bioenergetic index of reproductive potential. Can. J. Fish. Aquat. Sci., 57: 2433-2442.

MARTEINSDOTTIR, G., and A. STEINARSSON. 1998. Maternal influence on the size and viability of Iceland cod Gadus morhua eggs and larvae. J. Fish Biol., 52: 1241-1258.

MARTEINSDOTTIR, G., and K. THORARINSSON. 1998. Improving the stock-recruitment relationship in Icelandic cod (Gadus morhua) by including age diversity of spawners. Can. J. Fish. Aquat. Sci., 55: 1372-1377.

MOUNTAIN, D. G. 1989. TEMPEST: A computer program for estimating temperature on the Northeast Continental Shelf. NEFC, Woods Hole Laboratory, Lab. Ref. Doc., No. 89-02, 8 p

MORSE, W. 1989. Catchability, growth and mortality of larval fishes. Fish. Bull. U.S., 87: 417-446.

MURAWSKI, S. A., P. J. RAGO, and E. A. TRIPPEL. 2001. Impacts of demographic variation in spawning characteristics on reference points for fishery management. ICES J. Mar. Sci., 58: 1002-1014.

MYERS, R. A., N. J. BARROWMAN, J. A. HUTCHINGS, and A. A. ROSENBERG. 1995. Population dynamics of exploited fish stocks at low population levels. Science, 269: $1106-1108$.

O'BRIEN, L. 1999. Factors influencing the rate of sexual maturity and the effect on spawning stock for Georges Bank and Gulf of Maine Atlantic cod Gadus morhua stocks. J. Northw. Atl. Fish. Sci., 25: 179-203.

O'BRIEN, L., and N. J. MUNROE. 2001. Assessment of the Georges Bank Atlantic cod stock for 2001. NEFSC, Woods Hole Laboratory, Lab. Ref. Doc., No. 01-10: $126 \mathrm{p}$.

PAGE, F. H., and K. T. FRANK. 1989. Spawning time and egg stage duration in Northwest Atlantic haddock (Melanogrammus aeglefinus) stocks with emphasis on Georges and Browns Bank. Can. J. Fish. Aquat. Sci., 
46(Suppl. 1): 68-81.

PENNINGTON, M. and P. BERRIEN. 1984. Measuring the precision of estimates of total egg production based on plankton surveys. J. Plankton Res., 6: 869-879.

PLANQUE, B., and T. FREDOU. 1999. Temperature and the recruitment of Atlantic cod (Gadus morhua). Can. J. Fish. Aquat. Sci., 56: 2069-2077.

SCOTT B., G. MARTEINSDÓTTIR, and P. WRIGHT. 1999. Potential effects of maternal factors on spawning stock-recruitment relationships under varying fishing pressure. Can. J. Fish. Aquat. Sci., 56: 1882-1890.

SHANNON, C. E. 1948. A mathematical theory of communication. Bell System Tech. J., 27: 379-423.

SHEPHERD, J. G, J. G. POPE, and R. D. COUSENS. 1984. Variations in fish stocks and hypotheses concerning their links with climate. ICES Rapp. Proc.-Verb., 185: 255-267.

SIBUNKA, J. D., and M. J. SILVERMAN. 1984. MARMAP surveys of the continental shelf from Cape Hatteras, North Carolina, to Cape Sable, Nova Scotia (1977-1983). Atlas No. 1. Summary of operations. NOAA Tech. Memo NMFS-F/NEC-33: 306 p.

1989. MARMAP surveys of the continental shelf from Cape Hatteras, North Carolina, to Cape Sable, Nova Scotia (1984-1987). Atlas No. 3. Summary of operations. NOAA Tech. Memo. NMFS-F/ NEC-68, $197 \mathrm{p}$.

SMITH, W. G., and W. W. MORSE. 1993. Larval distribution patterns: Early signals for the collapse/recovery of Atlantic herring Clupea harengus in the Georges Bank area. Fish. Bull. U.S., 91: 338-347.

SUNDBY, S. 2000. Recruitment of Atlantic cod stock in relation to temperature and advection of copepod populations. Sarsia, 85: 277-298.

TAYLOR, M. H., and C. BASCUNAN. 1998. Description of the 1997 oceanographic condition on the northeast continental shelf. NEFSC, Woods Hole Laboratory, Lab.
Ref. Doc., No. 98-01, 112 p.

1999. Description of the 1998 oceanographic condition on the northeast continental shelf. NEFSC, Woods Hole Laboratory, Lab. Ref. Doc., No. 99-01, $91 \mathrm{p}$.

2000. Description of the 1999 oceanographic condition on the northeast continental shelf. NEFSC, Woods Hole Laboratory, Lab. Ref. Doc., No. 00-01, $120 \mathrm{p}$.

2001. Description of the 2000 oceanographic condition on the northeast continental shelf. NEFSC, Woods Hole Laboratory, Lab. Ref. Doc., No. 01-01, $93 \mathrm{p}$.

TAYLOR, M. H., and D. W. ALMGREN. 1996a. Description of the 1994 oceanographic condition on the northeast shelf. NEFSC, Woods Hole Laboratory, Lab. Ref. Doc., No. 96-07, 101 p.

1996b. Description of the 1995 oceanographic condition on the northeast continental shelf. NEFSC, Woods Hole Laboratory, Lab. Ref. Doc., No. 96-11, $125 \mathrm{p}$.

TAYLOR, M. H., and M. E. KILADIS. 1997. Description of the 1996 oceanographic condition on the northeast continental shelf. NEFSC, Woods Hole Laboratory, Lab. Ref. Doc., No. 97-16, 118 p.

THOMPSON, A. B., and J. D. RILEY. 1981. Egg and larval development studies in the North Sea cod (Gadus morhua L.). ICES Rapp. Proc.-Verb., 178: 553-59.

TRIPPEL, E. A. 1998. Egg size and viability and seasonal offspring production of young Atlantic cod. Trans. Am. Fish. Soc., 127: 339-359.

TRIPPEL, E. A., O. S. KJESBU, and P. SOLEMDAL. 1997. Effects of adult age and size structure on reproductive output in marine fishes. In: Early life history and recruitment in fish populations. R. C. Chambers, and E. A. Trippel (eds.). Chapman and Hall, New York, p. $31-62$. 
